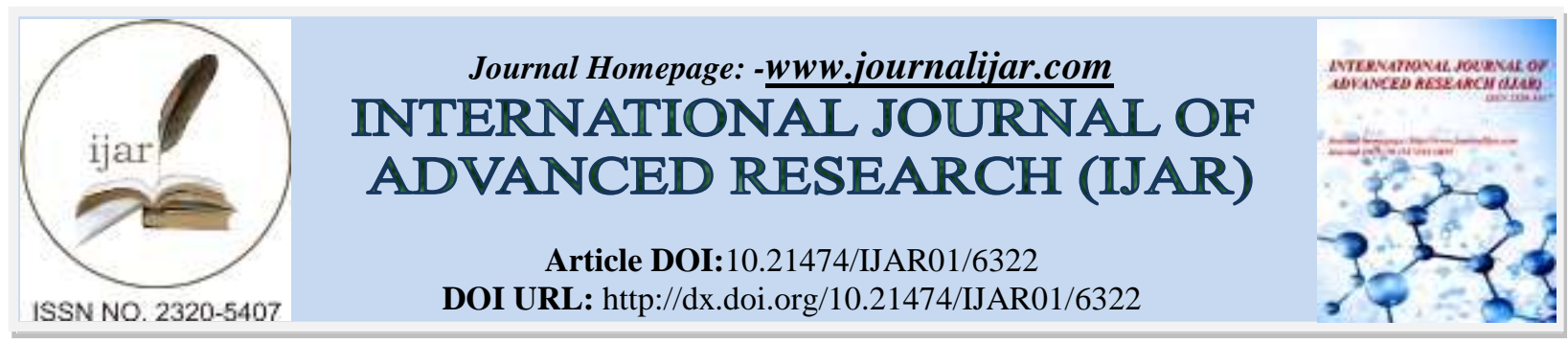

RESEARCH ARTICLE

\title{
EVIDENCE OF DNA DAMAGE IN SUBJECTS WITH SEVERE HYPOTHYROIDISM AND DYSLIPIDEMIA.
}

\author{
Athulya Rajendran ${ }^{1}$, Muhammed Ashraf $\mathrm{K}^{2}$, Vidya $\mathrm{PS}^{3}$ and Dinesh Roy $\mathrm{D}^{4}$. \\ 1. Department of Zoology, SreeNarayana College, Cherthala- 688582, Kerala. \\ 2. Associate Professor, Department of Biochemistry, Govt. Medical College, Malapuram-676121, Kerala. \\ 3. Assistant Professor, Department of Zoology, SreeNarayana College, Cherthala- 688582, Kerala. \\ 4. Genetika, Centre for Advanced Genetic Studies, Pettah P O, Thiruvananthapuram - 695024, Kerala.
}

\section{Manuscript Info}

\section{a.n. \\ Manuscript History}

Received: 16 November 2017

Final Accepted: 18 December 2017

Published: January 2018

\section{Key words:-}

Hypothyroidism, Dyslipidemia,

Cardiovascular disease and Cytokinesis-

block micronuclei assay.

\section{Abstract}

Thyroid diseases are one of the commonly occurring endocrine disorders worldwide. About 42 million people in India suffer from varied thyroid disorders. Thyroid hormones significantly affect lipoprotein metabolism as well as some CVD risk factors, thus influencing the overall CVD risk. The goal of the present study was to evaluate the evidence of DNA damage in subjects with severe hypothyroidism and dyslipidemia. The present study consists of 50 study subjects suffering from hypothyroidism along with dyslipidemia and 20 healthy control subjects. The extent of DNA damage was quantified by Cytokinesis-Block Micronuclei (CBMN) assay. Detailed demographic, clinical and lifestyle characteristics were compared with subjects. The micronuclei frequency was significantly elevated in study subjects as compared with that of control subjects. Various risk factors such as demographic, biochemical, hormonal and lifestyle characters were showed increased micronuclei, which leads to CVD. Thyroid disorders should be recognized and treated. Cardiovascular risk factors can be reduced by optimal metabolic control and lifestyle modification.

Copy Right, IJAR, 2018,. All rights reserved.

\section{Introduction:-}

Thyroid hormone plays an important role on various aspects of metabolism, development and differentiation of cells (Yen, 2001). The thyroid gland secretes the thyroid hormones, thyroxine (T4) and the more biologically active form triiodothyronine (T3) (Shah and Joshi, 2011). Thyroid function regulates a wide array of metabolic parameters. Thyroid function significantly affects lipoprotein metabolism as well as some cardiovascular disease (CVD) risk factors, thus influencing overall CVD risk (Duntas, 2002; Canaris et al., 2000). Indeed, a linear increase in total cholesterol (TC), low-density lipoprotein cholesterol (LDL-C) and triglycerides (TGs) and a linear decrease in highdensity lipoprotein cholesterol (HDL-C) levels have been observed with increasing TSH (Asvold et al., 2007).

Thyroid dysfunction is often associated with dyslipidemia and disturbed mineral metabolism. It is known that overt hypothyroidism leads to an increase in plasma cholesterol levels (Maratou et al., 2009). Hypothyroid patients have increased levels of TC and LDLC (Canaris et al., 2000). Indeed, hypothyroidism is a common cause of secondary dyslipidemia (Stone, 2007).Over 90\% of overt hypothyroid patients have hyperlipidemia (O'Brien et al., 1993). 
Serum total cholesterol and LDL cholesterol levels are increased by approximately $30 \%$ in patients with overt hypothyroidism (Martinez et al., 1998).

Resh et al., (2002) found that hypothyroidism was associated with enhanced oxidative stress and lipid peroxidation, DNA damage and supposed that this might lead to the development and progression of atherosclerosis (Klein, 2001). A number of techniques are used to detect DNA damage, as opposed to the biological effects (e.g. micronuclei, mutations, structural chromosomal aberrations) that result from DNA damage, have been used to identify substances with genotoxic activity. For genetic damage assessment, chromosomal damage in peripheral blood lymphocytes using the Cytokinesis-Block micronucleus (CBMN) assay. The CBMN assay is a well known cytogenetic test method to assess the genetic effects of spontaneously and mutagenically induced DNA damage (Fenech, 2007).

Hypothyroidism and dyslipidemia are the major risk factors of cardiovascular diseases (CVD). Treatment of dyslipidemia and hypothyroidism can reduce the risk of CVD. Patients who have higher baseline serum lipid values when hypothyroid will have greater reductions in serum lipid concentrations after the initiation of thyroid hormone replacement (Tanis, 1996). In India there are no national epidemiological data on the prevalence of these diseases that cover the entire country and no systematic studies were conducted to evaluate molecular and genetic mechanism underlying in subjects with hypothyroidism and dyslipidemia. Hence the present study was undertaken to evaluate the evidence of DNA damages in subjects with severe hypothyroidism and dyslipidemia.

\section{Materials and Methods:-}

Fifty subjects with severe hypothyroidism and dyslipidemia were selected as the study subjects and twenty subjects without any chronic illness were selected as control for this study. All these subjects were referred from Cardiology Department of General Hospital, Trivandrum and from Hridayalaya Institute for Preventive Cardiology, Trivandrum, to Genetika, Centre for Advanced Genetic studies, Trivandrum, Kerala. Detailed socioeconomic, demographic, anthropometric information's were recorded using proforma. Biochemical characteristics such as FBS, Total cholesterol, HDL, LDL and Triglycerides were also recorded.

Eight $\mathrm{ml}$ of blood sample was collected by venipuncture. Four $\mathrm{ml}$ of blood was transferred into sodium heparinized vacutainers for quantifying the extent of somatic DNA damages by Cytokinesis-Block Micronuclei (CBMN) assay. The remaining four $\mathrm{ml}$ of blood was transferred into a plain tube. Blood was allowed to clot, serum separated immediately. Blood sugar and lipid profile were estimated using semi-automated clinical chemistry analyzer.

Two $\mathrm{ml}$ blood was added to a culture tube containing $10 \mathrm{ml}$ RPMI 1640 medium supplemented with 100units $/ \mathrm{mL}$ penicillin, $100 \mu \mathrm{g} / \mathrm{mL}$ streptomycin, $15 \%$ fetal bovine serum and $10 \mu \mathrm{g} / \mathrm{mL}$ phytohaemagglutinin. Cytochalasin B was added to the cultures at a final concentration of $4.5 \mu \mathrm{g} / \mathrm{mL}$ (Sigma) after $44^{\text {th }}$ hours. Cells were harvested after $72^{\text {th }}$ hour incubation, and they were treated with a hypotonic $\mathrm{KCl}$ solution $(0.075 \mathrm{M} \mathrm{KCl})$ for $10 \mathrm{~min}$ and fixed in fresh fixative solution (methanol: acetic acid, 3:1). The cells were dropped onto slides and the slides were air dried and stained with $10 \%$ Giemsa. Micronucleated cells were analyzed under light microscopy at 100X magnification. The number of micronuclei is not less than 1000 binucleated cells were scored and the distribution of micronuclei among binucleated cells was recorded.

\section{Observations and Results:-}

In the present study, 50 study subjects and 20 control subjects were considered. The study subjects, age ranged from 31 to 63 years. Their average age was 41.62 years. In control subjects, their age ranged from 22 to 49 years and their average age was 37.15 years. 31 study subjects have sedentary type of occupation and remaining has non sedentary type of occupation. Parental consanguinity was reported only in 20 study subjects. 4 study subjects with high socioeconomic status, 29 were average socioeconomic status and 17 were low socioeconomic status. Out of 50 study subjects, 31 have history of diabetes, 28 have history of hypertension and 19 have history of CAD. Lifestyle characters of subjects include smoking, chewing and alcohol consumption. 14 study subjects were smokers, 15 were chewers and 16 were drinkers. Regular exercise was noticed in 14 study subjects. 41 subjects were non vegetarians and 9 subjects were vegetarians. 
The distribution of mean CBMN frequency of the study subjects and control subjects was observed. The mean CBMN frequency of study subjects and control subjects was 12.56 and 10.34 respectively. Study subjects have highest mean CBMN frequency than control subjects.

Table 1:- Distribution of mean CBMN frequency according to demographic characters

\begin{tabular}{|l|l|l|l|l|}
\hline Category & Variables & Numbers & Percentage $(\%)$ & Mean CBMN Frequency \\
\hline \multirow{3}{*}{ Age (Years) } & $\leq 45$ & 37 & 74 & 12.46 \\
\cline { 2 - 4 } & $>45$ & 13 & 26 & 12.84 \\
\hline \multirow{3}{*}{ Bex } & Male & 23 & 46 & 12.38 \\
\cline { 2 - 4 } & Female & 27 & 54 & 12.71 \\
\hline \multirow{3}{*}{ BMI $\left(\mathrm{Kg} / \mathrm{m}^{2}\right)$} & $\leq 5$ & 44 & 88 & 12.54 \\
\cline { 2 - 4 } & $>5$ & 6 & 12 & 12.72 \\
\hline \multirow{3}{*}{ Socio Economic Status } & $<25$ & 10 & 20 & 11.54 \\
\cline { 2 - 5 } & $25-30$ & 28 & 56 & 12.64 \\
\cline { 2 - 5 } & $>30$ & 12 & 24 & 13.23 \\
\cline { 2 - 5 } & High & 4 & 8 & 12.31 \\
\cline { 2 - 5 } & Average & 29 & 58 & 12.45 \\
\cline { 2 - 5 } & Low & 17 & 34 & 12.79 \\
\hline Nature of Occupation & Sedentary & 31 & 62 & 12.86 \\
\cline { 2 - 5 } & Non sedentary & 19 & 38 & 12.07 \\
\hline Parental Consanguinity & Yes & 20 & 40 & 12.9 \\
\cline { 2 - 5 } & No & 30 & 60 & 12.33 \\
\hline
\end{tabular}

Distribution of mean CBMN frequency according to demographic characters of subjects was given in Table 1. Advanced age of the subjects have highest mean CBMN frequency (12.84). Majority of the subjects were females and they having highest mean CBMN frequency. Subjects with $>5$ birth order were showed mean CBMN frequency of 12.72. Over weight and obese subjects were showed highest mean CBMN frequency than normal ones. Most of the subjects were having average socioeconomic status. Subjects with low socioeconomic status were showed highest mean CBMN frequency of 12.79. 31 subjects were works as sedentary workers and 19 were non sedentary workers. Sedentary workers showed highest mean CBMN frequency (12.86). 20 subjects with parental consanguinity and they having highest mean CBMN frequency of 12.33 .

Table 2:-Distribution of mean CBMN frequency according to clinical characters

\begin{tabular}{|c|c|c|c|c|}
\hline Category & Variables & Numbers & Percentage (\%) & Mean CBMN Frequency \\
\hline \multirow{3}{*}{ H/o Diabetes } & Yes & 31 & 62 & 12.69 \\
\cline { 2 - 5 } & No & 19 & 38 & 12.35 \\
\hline \multirow{3}{*}{ H/o Hypertension } & Yes & 28 & 56 & 12.69 \\
\cline { 2 - 5 } & No & 22 & 44 & 12.39 \\
\hline \multirow{3}{*}{ H/o CAD } & Yes & 19 & 38 & 12.92 \\
\cline { 2 - 5 } & No & 31 & 62 & 12.33 \\
\hline
\end{tabular}

Distribution of mean CBMN frequency according to clinical characters of subjects was given in Table 2. History of diabetes was reported in 31 out of 50 study subjects. History of hypertension was reported in 28 out of 50 study subjects. History of CAD was reported in 19 out of 50 study subjects. Subjects with H/o Diabetes, H/o Hypertension and H/o CAD were showed increased micronuclei frequency.

Table 3:- Distribution of mean CBMN frequency according to lifestyle characters

\begin{tabular}{|c|c|c|c|c|}
\hline Category & Variables & Numbers & Percentage (\%) & Mean CBMN Frequency \\
\hline \multirow{3}{*}{ Habit of Smoking } & Yes & 14 & 28 & 12.78 \\
\cline { 2 - 5 } & No & 36 & 72 & 12.47 \\
\hline \multirow{3}{*}{ Habit of Chewing } & Yes & 15 & 30 & 12.8 \\
\cline { 2 - 5 } Alcohol Consumption & No & 35 & 70 & 12.46 \\
\cline { 2 - 5 } & Yes & 16 & 68 & 12.84 \\
\hline \multirow{3}{*}{ Regular Exercise } & No & 34 & 28 & 12.42 \\
\cline { 2 - 5 } & Yes & 14 & 72 & 11.84 \\
\hline
\end{tabular}




\begin{tabular}{|c|c|c|c|c|}
\hline \multirow{2}{*}{ Diet } & Non Vegetarian & 41 & 82 & 12.58 \\
\cline { 2 - 5 } & Vegetarian & 9 & 18 & 12.44 \\
\hline
\end{tabular}

Distribution of mean CBMN frequency according to demographic characters of subjects was given in Table 3. The habit of smoking was reported in 14 out of 50 study subjects. The habit of chewing was reported in 15 out of 50 study subjects and alcohol consumption was reported in 16 out of 50 study subjects. The regular exercise was reported in 14 out of 50 study subjects. In 50 study subjects 4 subjects were high type of physical activity, 17 subjects were average type of physical activity and 29 subjects were poor type of physical activity. Subjects having the habit of smoking, chewing and alcohol consumption were also showed highest mean CBMN frequency. Subjects were do regular exercise and they having lowest mean CBMN frequency. Majority subjects were non vegetarians with highest mean CBMN frequency of 12.58 .

Table 4:- Distribution Of Mean Cbmn Frequency According To Biochemical And Hormonal Characters

\begin{tabular}{|c|c|c|c|c|}
\hline Category & Variables & Numbers & Percentage (\%) & Mean CBMN Frequency \\
\hline \multirow[t]{2}{*}{ FBS (mg/dl) } & $\leq 110$ & 18 & 36 & 11.97 \\
\hline & $>110$ & 32 & 64 & 12.89 \\
\hline \multirow[t]{2}{*}{ Total Cholesterol $(\mathrm{mg} / \mathrm{dl})$} & $<200$ & 11 & 22 & 12.06 \\
\hline & $\geq 200$ & 39 & 78 & 12.7 \\
\hline \multirow[t]{2}{*}{$\mathrm{HDL}(\mathrm{mg} / \mathrm{dl})$} & $<35$ & 22 & 44 & 12.96 \\
\hline & $\geq 35$ & 28 & 56 & 12.24 \\
\hline \multirow[t]{2}{*}{$\operatorname{LDL}(\mathrm{mg} / \mathrm{dl})$} & $<130$ & 21 & 42 & 11.83 \\
\hline & $\geq 130$ & 29 & 58 & 13.09 \\
\hline \multirow[t]{2}{*}{ Triglycerides (mg/dl) } & $<150$ & 16 & 32 & 12.2 \\
\hline & $\geq 150$ & 34 & 68 & 12.73 \\
\hline \multirow[t]{3}{*}{$\mathrm{T} 3$ (ng/dl) } & $<20$ & 6 & 12 & 13.42 \\
\hline & $20-60$ & 28 & 56 & 12.84 \\
\hline & $>60$ & 16 & 32 & 11.7 \\
\hline \multirow[t]{2}{*}{$\mathrm{T} 4(\mu \mathrm{g} / \mathrm{dl})$} & $<2$ & 21 & 42 & 12.92 \\
\hline & $\geq 2$ & 29 & 58 & 12.3 \\
\hline \multirow[t]{2}{*}{ TSH (mIU/L) } & $\leq 10$ & 29 & 58 & 12.26 \\
\hline & $>10$ & 21 & 42 & 12.97 \\
\hline
\end{tabular}

Biochemical and hormonal characters of the subjects were given in Table 4. Subjects with abnormal level in biochemical characters such as FBS, total cholesterol, HDL, LDL, triglycerides were showed highest mean CBMN frequency. Hypothyroid subjects with lower T3, T4 and higher TSH were showed increased micronuclei frequency.

\section{Discussion:-}

Hypothyroidism and dyslipidemia shows an increasing trend with age in both males and females. According to Agarwal et al., (2011) reported that thyroid disease is much more prevalent in women than in men. The present study also showed majority of hypothyroid subjects were females and they having highest micronuclei frequency. Humayun et al., (2009) reported the increased prevalence of dyslipidemia in older women; it may be related to the hormonal changes in pre and post menopausal. Thus the increase in hypothyroidism and dyslipidemia with progression of age observed in the present study is in agreement with that of previous studies.

Tanner, (2005) reported that overweight and obesity continue to increase substantially worldwide, affecting all ages, sexes and races. Dyslipidemia is directly related with BMI, showing that with the increase in the BMI the trend of dyslipidemia rises in both females and males. It is evident that there is a general trend of increase in dyslipidemia with increasing BMI in both males and females with age. This is consistent with the findings of Malnick et al., (2006). In the present study, majority of the study subjects had BMI greater than $30 \mathrm{~kg} / \mathrm{m}^{2}(24 \%)$ and these subjects showed the highest mean CBMN frequency of 13.23.

The present study identifies hypothyroidism and dyslipidemia as a common disorder and is leading cause for coronary heart diseases. Hypothyroid patients have increased levels of TC and LDL-C. Indeed, hypothyroidism is a common cause of secondary dyslipidemia (Canaris et al., 2000). In the present study, subjects with total cholesterol 
greater than $200 \mathrm{mg} / \mathrm{dl}$ estimated as highest mean CBMN frequency. Abnormal level in HDL, LDL and triglyceride were showed highest mean CBMN frequency.

Fan et al., (2008) observed a positive correlation between life time average drinking intensity and prevalence of metabolic syndrome. The present study indicated an increased mean CBMN frequency in alcoholics (12.84) than others. In the present study mean CBMN frequency was highest in subjects with habit of smoking $(\mathrm{n}=14)(12.78)$ and subjects with habit of chewing $(\mathrm{n}=15)(12.80)$.

Kontush(2008) reported that dyslipidemia is caused by several factors such as obesity, physical inactivity, cigarette smoking, excess alcohol consumption, high-carbohydrate diets ( $>60 \%$ of total energy), other diseases such as type 2 diabetes mellitus, chronic renal failure, nephrotic syndrome, and genetic predisposition. In the present study also, hypothyroidism and dyslipidemia has a positive correlation between age, birth order, physical inactivity, BMI, smoking, alcohol consumption, diet, and other diseases such as diabetes, hypertension and genetic predisposition. Here the lifestyle associated risk factors have a major role in CVD.

\section{Conclusion:-}

From the study, it can be concluded that thyroid hormones significantly affect lipoprotein metabolism causing varied effects on cholesterol levels. There is a positive correlation between micronuclei frequency with hypothyroid and dyslipidemic subjects. Thyroid dysfunction also predisposes an individual to cardiovascular risk factors, some are modifiable and others are not. Primary recommendation was to underlying thyroid disorders should be recognized and treated. Cardiovascular risk factors can reduce by optimal metabolic control and lifestyle modification.

\section{Reference:-}

1. Agarwal, G., Sudhakar, M. K., Singh, M., Senthil, N., Rajendran, A. (2011). "The prevalence of thyroid dysfunction among South Indian women with Metabolic Syndrome” . J. of clinical \& diagnostic research; 5(2): 213216.

2. Asvold, B. O., Vatten, L. J., Nilsen, T. I., Bjoro T. (2007). "The associationbetween TSH within the reference range and serum lipid concentrations in a population-based study". The HUNT Study. Eur J Endocrino; 156: 181-6.

3. Canaris, G. J., Manowitz, N. R., Mayor, G., Ridgway, E. C. (2000). "The Colorado thyroid disease prevalence study”. Arch Intern Med; 160(4): 526-34.

4. Duntas, L. H. (2002). "Thyroid disease and lipids". Thyroid; 12: 287-93.

5. Fan, A. Z., Russell, M., Stranges, S., et al. (2008).“Association of lifetime alcohol drinking trajectories with cardiometabolic risk”. J ClinEndocrinolMetab ; 93: 154-61.

6. Fenech, M. (2007). "Cytokinesis-block micronucleus cytome assay". Nat Protoc; 2:1084-1104.

7. Humayun, A., Shah, A. S., Alam, S., Hussein, H. (2009). "Relationship of body mass index and dyslipidemia in different age groups of male and female population of Peshawar". JAMC;21: 141-144.

8. Klein, I and Ojamaa, K (2001). "Thyroid hormone and the cardiovascular system". N Engl J Med;344: 501-509.

9. Kontush, A., Guérin, M., Chapman, M. J. (2008). "Spotlight on HDL-raising therapies: Insights from the torcetrapib trials". Nat ClinPractCardiovasc Med; 5:329-36.

10. Malnick, S. D. H., Knobler, H. B. (2006). “The Medical Complications of Obesity". Q J Med; 99:565-79.

11. Maratou, E., Hadjidakis, D., Kollias, A., Tsegka, K., Peppa, M., Alevizaki, M., et al. (2009). "Studies of insulin resistance in patients with clinical and subclinical hypothyroidism". Eur J Endocrinol; 130: 28-35.

12. Martinez-Triguero, M. L., Hernandez-Mijares, A., Nguyen, T. T., et al., (1998)."Effect of thyroid hormone replacement on lipoprotein(a), lipids, and apolipoproteins in subjects with hypothyroidism". Mayo ClinProc; 73:837841.

13. O'Brien, T., Dineen, S. F., O'Brien, P. C., Palumbo, P. J. (1993)."Hyperlipidemia in patients with primary and secondary hypothyroidism". May ClinProc; 68:860-866.

14. Resh, U., Helsel, G., Tatzber, F., Sinzinger, H. (2002). "Anti-oxidant status in thyroid dysfunction”. Clin. Chem. Lab. Med; 40: 1132-1134.

15. Shah, S. N., Joshi, S. R. (2011).“Think thyroid: Special Issue on Indian Thyroid Guidelines”. Journal of Associations of Physicians of India; 59(1).

16.Stone, N. J. (2007). "Secondary causes of hyperlipidemia". Med Clin North Am; 78: 117-41.1; 156: 181-6.

17. Tanis, B. C., Westendorp, G. J., Smelt, H. M. (1996). "Effect of thyroid substitution on hypercholesterolemia in patients with subclinical hypothyroidism: a reanalysis of intervention studies'. ClinEndocrinol; 44:643-649.

18. Tanner, (2005). "The Scientific Definition of Obesity and its Danger". Mercola Author. Total Health Program.

19. Yen, P. M. (2001). "Physiological and molecular basis of thyroid hormone action". Physiol Rev; 81: 1097-1142. 